\title{
Split hand/split foot malformation, deafness, and mental retardation with a complex cytogenetic rearrangement involving $7 q 21.3$
}

\author{
Jaakko Ignatius, Sakari Knuutila, Stephen W Scherer, Barbara Trask, Juha Kere
}

Department of Medical Genetics, Väestöliitto, The Family Federation of Finland, Helsinki, Finland

J Ignatius

Department of Medical Genetics, University of Helsinki, PO Box 21,

Haartmaninkatu 3, FIN-00014, Helsinki, Finland

S Knuutila

J Kere

\section{Department of}

Molecular and Medical Genetics, University of Toronto, Ontario, and Department of Genetics,

Research Institute, The Hospital for Sick Children,

Toronto, Ontario, Canada $\mathrm{S}$ W Scherer

\section{Department of}

Molecular

Biotechnology,

University of

Washington, Seattle, WA, USA

B Trask

Correspondence to: Dr Kere.

Received 25 October 1995 Revised version accepted for publication 22 December 1995

\begin{abstract}
Split hand/split foot malformation (SHSF) has been described in several patients associated with cytogenetically visible rearrangements involving chromosome $7 q$. Characterisation of these patients has led to localisation of an autosomal dominant form of SHSF to 7q21-22; the locus has been designated SHFM1. We describe a patient with a complex, apparently balanced cytogenetic rearrangement, including a translocation breakpoint at 7 q21.3 near the DSS1 gene. In addition to ectrodactyly of all four limbs, the patient has congenital deafness, submucous cleft palate, microcephaly, and mental retardation. This patient represents an additional case of syndromic ectrodactyly related to the SHFM1 gene region, which may be responsible for both syndromic and non-syndromic ectrodactyly. ( $($ Med Genet 1996;33:507-510)
\end{abstract}

Key words: split hand/split foot; human chromosome $7 \mathrm{q}$; translocation; congenital deafness.

Split hand/split foot deformity (SHSF), or ectrodactyly, is the result of maldevelopment of the central rays of the limb buds and can occur as an isolated defect or as a part of a variety of syndromes. ${ }^{12}$ Both the non-syndromic and syndromic ectrodactylies may be sporadic or inherited as an autosomal dominant trait or rarely as an autosomal recessive or $\mathrm{X}$ linked recessive trait. ${ }^{34}$ Most patients reported had normal karyotypes. In some patients, however, either syndromic or non-syndromic ectrodactyly has been described in association with cytogenetic abnormalities involving chromosome $7 \mathrm{q}^{5-20}$ These findings have led to the localisation of a locus for an autosomal dominant form of SHSF to 7q21-q22, designated SHFM1 (MIM 183600). ${ }^{4}$ Based on linkage studies, at least one additional autosomal locus, designated SHFM3, exists. ${ }^{2122}$

We describe a patient with syndromic ectrodactyly associated with a complex cytogenetic rearrangement involving the $7 \mathrm{q} 21.3$ region and the molecular characterisation of the rearrangement.

\section{Case report}

The patient, a 54 year old male, had healthy, non-consanguineous parents. There is no fam- ily history of limb malformations, mental retardation, cleft palate, or hearing loss. The pregnancy and delivery were normal. Immediately after birth, the child was found to have malformations in all four limbs. Developmental milestones were delayed and he walked at 3 years. The patient was found to be deaf at the age of 6 months and he never learned to speak. First psychological tests were performed at 10 years of age, and he was found to be severely mentally retarded (IQ 30). He has been permanently institutionalised since the age of 42 .

On clinical examination, the patient was found to be a mentally retarded, deaf-mute man with an outgoing character. He was able to communicate with gestures. He had a peculiar facial appearance with microcephaly, triangular face, downward slanting palpebral fissures, small ears with poorly developed folds, and a prominent lower jaw with prognathism (fig 1). He had a submucous cleft palate and split hand/split foot anomaly in all four limbs. There was bilateral upper limb ectrodactyly with absent second and third rays on the left and absent second ray and missing third finger on the right. Bilateral split foot anomaly was observed in the lower limbs (fig 1). The skin was normal and the body hair distribution was masculine. There were no signs of heart, lung, or abdominal organ dysfunction, and the urogenital organs were normal, including normal intravenous urography results. On electric response audiometry, no responses at $90 \mathrm{~dB}$ and $100 \mathrm{~dB}$ could be obtained.

\section{Cytogenetic studies}

Karyotype analysis by trypsin-Giemsa banding was performed on phytohaemagglutinin stimulated lymphocyte cultures. $G$ banding analysis showed a complex karyotype: $46, \mathrm{XY}$, $\operatorname{inv}(1)(\mathrm{q} 21 \mathrm{q} 32), \mathrm{t}(4 ; 7)(\mathrm{q} 31.1 ; \mathrm{q} 21.3), \quad \operatorname{inv}(11)$ (p15.1q23) (fig 2). This interpretation was suggested by the cytogenetic study and was supported by chromosome painting and in situ hybridisation results. The mechanism of the inversions and translocations in this patient remains undetermined. When this patient was first studied in 1976, his father had already died; his mother, brother, and sister had normal karyotypes (A de la Chapelle, personal communication).

Chromosome painting by chromosome in situ suppression (CISS) hybridisation was performed using chromosome $1,4,7$, and 11 

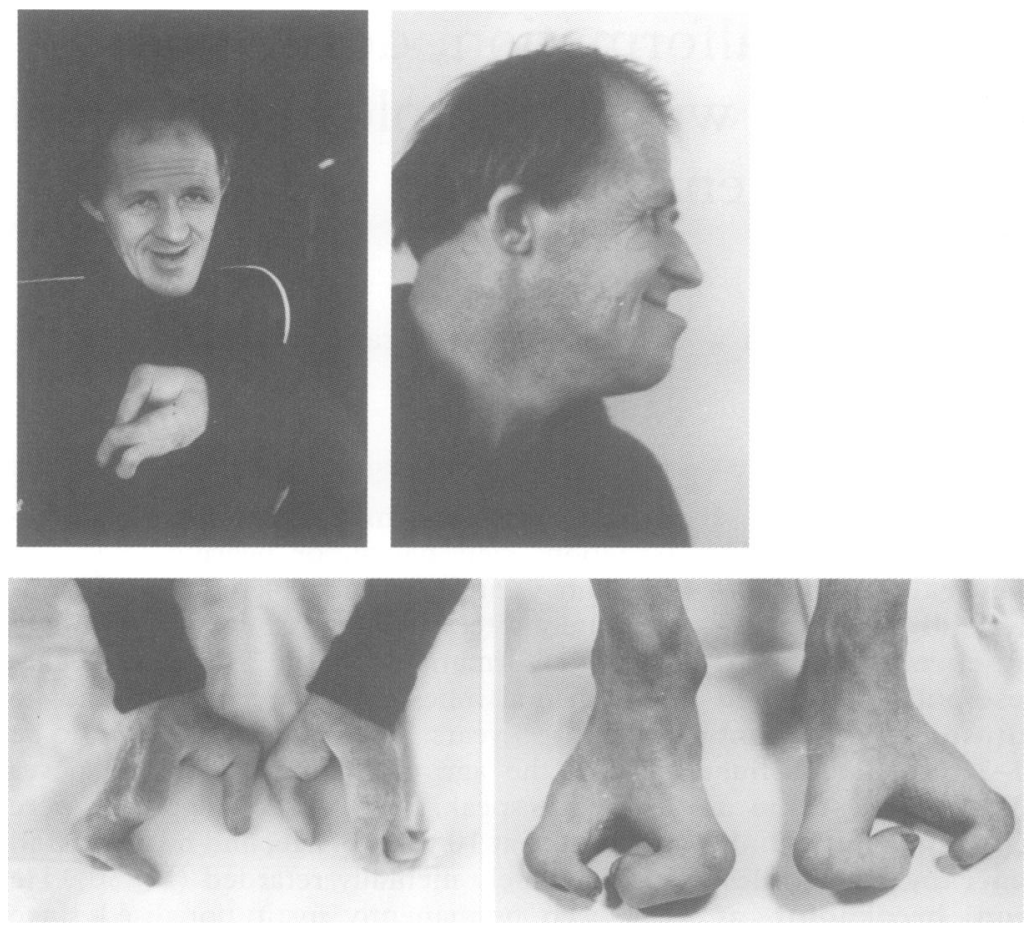

Figure 1 (Above) Facial features of the patient. Note triangular facies, microcephaly, prognathism, and small, malformed ears. (Below) Split hand/split foot deformity is present in all four limbs.

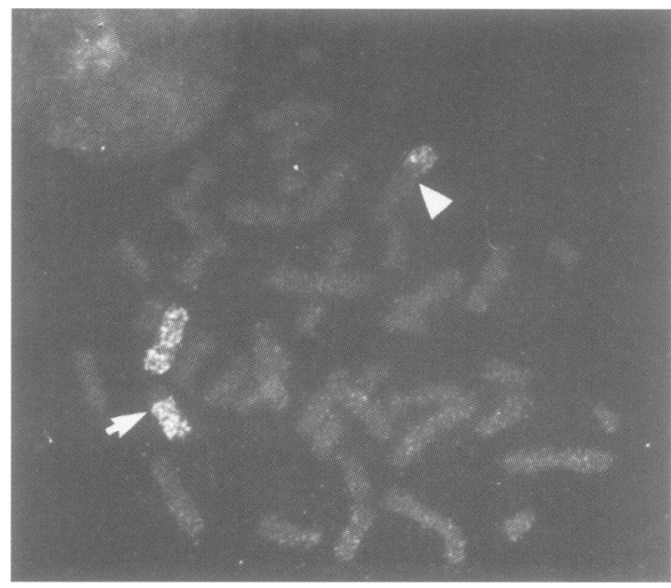

Figure 3 Chromosome painting with chromosome 7 specific whole chromosome suppressed library.

Translocation between chromosomes 4 and 7 is confirmed using this paint and a paint for chromosome 4. No other chromosomes show hybridisation. Triangle indicates der(7) and arrow $\operatorname{der}(4)$.

The probes were labelled with biotin-11-dUTP (Sigma Chemical Co, St Louis, MO) and detected using fluorescein labelled avidin (FITC). ${ }^{23}$ Chromosome painting was consistent with the results of $G$ banding analysis and did not suggest the presence of a complicated three or four way translocation between chromosomes 1, 4, 7, and 11 (fig 3).

The location of the translocation breakpoint at $7 \mathrm{q}$ was refined earlier with fluorescence in situ hybridisation (FISH) analysis using YAC DNA probes mapped to the region. ${ }^{24}$ Three YAC probes from the region (HSC7E578, HSC7E1131, and HSC7E571) were shown by FISH to cross the breakpoint in this patient (patient T6 in reference 24). These findings mapped the breakpoint to the same minimal critical region for SHFM1 as observed in several other patients with both syndromic and non-syndromic ectrodactyly.

To refine the breakpoint further, a cosmid probe, $\cos 177 \mathrm{c} 8$, which was isolated by probing with a new gene DSS1 (Deleted in Split hand/ Split foot 1 , cloned from the SHFM1 critical region $^{25}$ ) was used in FISH. The cosmid was

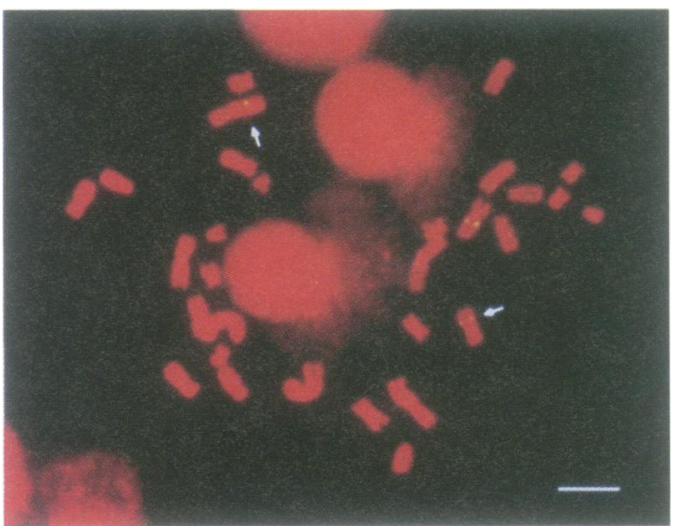

Figure 4 FISH analysis of the patient's chromosomes with the $\cos 177 c 8$ probe. Signal is seen on three chromosomes, the normal chromosome 7, der(7), and der(4), indicating that the cosmid spans the translocation breakpoint. Arrows indicate der(4) (top left) and der(7) chromosomes. Size bar $=5 \mu \mathrm{m}$.

Figure 2 Partial karyotypes from three metaphase mitoses. Arrows indicate chromosomal breakpoints. The cytogenetic interpretation is 46,XY,inv(4) (q21q32),t(4;7) (q31.1; q21.3), inv(11) (p15.1q23). 
Ectrodactyly associated with $7 q 2$ rearrangements

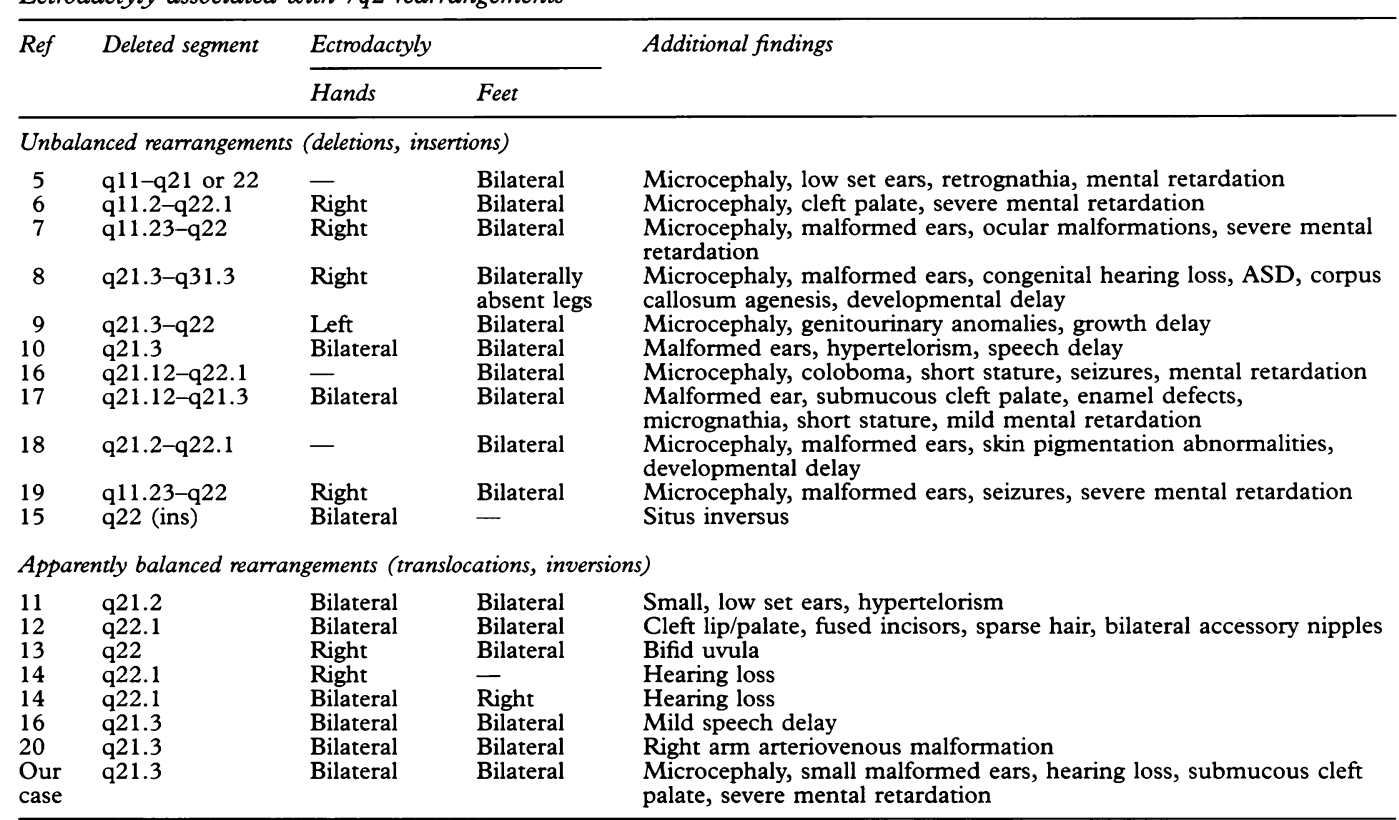

biotinylated, hybridised to metaphase spreads prepared from Epstein-Barr virus transformed lymphoblasts derived from the patient, and detected with FITC-avidin. ${ }^{26}$ This probe was found to cross the chromosome 7 breakpoint in the patient (fig 4), mapping the breakpoint in the immediate vicinity of DSS1.

\section{Discussion}

Before the present case, at least 18 cases with ectrodactyly associated with a visible cytogenetic abnormality involving band $7 \mathrm{q} 2$ have been described (table). The patients represent both syndromic and non-syndromic ectrodactyly, including one large family with a highly variable clinical picture and cases of both syndromic and non-syndromic ectrodactyly in the same pedigree. ${ }^{14}$ Clinical subtyping of the present case as well as other published cases in the spectrum of ectrodactyly associated syndromes is difficult. Several cases may be misleading because of the complex chromosome rearrangements found in different patients. Our patient's rearrangement involves a breakpoint in at least six chromosomal bands. Some of these breakpoints may disrupt genes with phenotypic consequences, others may be harmless. Furthermore, molecular deletions or duplications may have occurred in conjunction with rearrangements interpreted cytogenetically as simple translocations or inversions. Among the associated findings in our patient, mental retardation, microcephaly, and small, malformed ears are non-specific and commonly associated with many different chromosomal abnormalities, including those of chromosomes 1, 4, and 11. Although these findings were often encountered in other published cases of ectrodactyly associated with $7 q$ rearrangements, especially $7 q$ deletions, they may not be directly related to the disruption of the SHFM1 locus.
Deafness and oral clefting have been described in several patients with syndromic ectrodactyly and a cytogenetic abnormality at 7q21-q22. In addition to the present case, at least three other patients have been described who also had hearing loss, which appears to be congenital, sensorineural, and often severe. ${ }^{814}$ Hearing loss as well as cleft palate are features of ectrodactyly-ectodermal dysplasia-cleft palate (EEC) syndrome (MIM 129900), but our patient did not have findings consistent with ectodermal dysplasia. Only a few patients with ectrodactyly associated with a cytogenetic abnormality involving 7q21-22 were reported to have sparse hair or enamel hypoplasia. ${ }^{12}{ }^{17}$ Deafness is also a part of the LADD (lacrimoauriculo-dento-digital) syndrome (MIM 149730) as well as ectrodactyly-hearing loss syndrome (MIM 220600), and cleft palate is a part of the ECP (ectrodactyly-cleft palate) syndrome (MIM 129830). As all these syndromes show variable expressivity, the classification of a single case may be difficult on clinical grounds only.

Interestingly, patients with both non-syndromic and syndromic ectrodactyly with various additional abnormalities have been found to have cytogenetic rearrangements involving the same region at $7 \mathrm{q} 21.3-\mathrm{q} 22.1$. Further analysis of this region has mapped the breakpoints for chromosomal rearrangements to a common interval both in syndromic and non-syndromic patients. ${ }^{24}$ In several patients with apparently balanced rearrangements, the translocation and inversion breakpoints have been mapped within a $700 \mathrm{~kb}$ interval in the SHFM1 critical region. Using three YAC probes, HSC7E578, HSC7E1131, and HSC7E571, the breakpoint was also mapped to the same region in the present patient. In this study, the cosmid probe $\cos 177 \mathrm{c} 8$ was shown to cross the breakpoint to define its location more precisely. The role of the DSS1 gene contained in part in the same 
cosmid probe is the subject of further study. ${ }^{25}$

The developmental defects in patients with syndromic ectrodactyly associated with involvement of $7 \mathrm{q}$ range widely (table). This observation speaks for a common aetiological association between the simple split hand/split foot anomaly and abnormalities often seen in association with this condition. At least some of these birth defects may result from a defect in the SHSF gene itself or from a group of tightly clustered developmental genes at 7q21.3-q22.1.

We thank Dr Sakari Turunen for bringing this patient to our attention and Dr Albert de la Chapelle for the initial diagnosis of the cytogenetic rearrangement that he made correctly in 1976. We thank Hillary Massa (University of Washington) for assistance with FISH and Dr Jim Evans for his early contributions to the analysis of this patient. JK is supported by the Academy of Finland, the Sigrid Juselius Foundation, the Finnish Academy of Finland, the Sigrid Juselius Foundation, the Finnish Cancer Organisations, and the Folkhälsan Institute of Genetics, 93ER61553 and FG06-93ER61662.

1 Schroer RJ. Split hand/split foot. Proc Greenwood Center 986;5:65-75.

2 Gorlin RJ, Cohen MM, Levin LS. Syndromes of the head and neck. 3rd ed. Oxford: Oxford University Press, 1990 716-20.

3 Faiyaz-ul-Haque $M$, Uhlhaas $S$, Knapp $M$, et al. Mapping of the gene for X-chromosomal split-hand/split-foot anomaly to Xq26-q26.1. Hum Genet 1993;91:17-19.

4 McKusick VA. Mendelian inheritance in man. 11 th ed. Baltimore: Johns Hopkins University Press, 1994.

5 Del Porto G, D'Alessandro E, De Matteis C, Lo Re ML, Ivaldi $M$, Di Fusco $C$. Delezione interstiziale del braccio ungo del cromosoma 7 e sue correlazioni cliniche $\mathrm{Pa}$ thologica 1983;75(suppl):268-71.

6 Pfeiffer RA. Interstitial deletion of a chromosome 7 (q11.2q22.1) in a child with split hand/split foot malformation. Ann Genet (Paris) 1984;27:45-8

7 Tajara EH, Varella-Garcia M, Gusson ACT. Interstitial long-arm deletion of chromosome 7 and ectrodactyly. $A m$ long-arm deletion of chromo

8 Morey AM, Higgins RR. Ectro-amelia syndrome associated with an interstitial deletion of 7q. Am F Med Genet 1990 35:95-9.

9 Rivera H, Sanchez-Corona J, Burgos-Fueules UR, Melendez-Ruiz MJ. Deletion of $7 \mathrm{q} 22$ and ectrodactyly. Genet Couns 1991;2:27-31.

10 Roberts SH, Hughes HE, Davies SJ, Meredith AL. Bilatera split hand and split foot malformation in a boy with a de novo interstitial deletion of 7q21.3. F Med Genet 1991;28: 479-81.

11 Sharland M, Patton MA, Hill L. Ectrodactyly of hands and feet in a child with a complex translocation including 7q21.2. Am $\mathcal{f}$ Med Genet 1991;39:413-14.

12 Akita S, Kuratomi H, Abe K, Harada N, Mukae N, Niikawa N. EEC syndrome in a girl with paracentric inversion (7) $(122.1 ; \mathrm{q} 36.3)$. Clin Dysmorphol 1993;2:62-7.

13 Naritomi K, Izumikawa $Y$, Tohma $T$, Hirayana K. Inverted insertion of chromosome $7 \mathrm{q}$ and ectrodactyly. $A m \mathcal{F} M e d$ Genet 1993;46:492-4.

14 Genuardi M, Pomponi MG, Sammito V, Bellussi A, Zollino $M$, Neri G. Split hand/split foot anomaly in a family segregating a balanced translocation with breakpoint on 7q22.1. Am $₹$ Med Genet 1993;47:823-31.

15 Koiffmann CP, Waintal A, de Souza DH, Gonzales $\mathrm{CH}$ Coates MV. Human situs determination and chromosomal constitution 46,XY,ins $(7 ; 8)(\mathrm{q} 22 ; \mathrm{q} 12 \mathrm{q} 24) . A m ~ f \mathrm{Med}$ Constitution 46,XY,in

16 Scherer SW, Poorkaj P, Allen T, et al. Fine mapping of the autosomal dominant split hand/split foot locus on chromosome 7, band q21.3-q22.1. Am ₹ Hum Genet 1994; 55:12-20

17 Nunes ME, Pagon RA, Disteche CJ, Evans JP. A contiguous gene deletion syndrome at $7 \mathrm{q} 21-\mathrm{q} 22$ and implications for a relationship between isolated ectrodactyly and syndromic ectrodactyly. Clin Dysmorphol 1994;3:277-86.

18 Marinoni JC, Stevenson RE, Evans JP, Geshuri D, Phelan MC, Schwartz CE. Split foot and developmental retardation associated with a deletion of three microsatellite markers in 7q21.2-q22.1. Clin Genet 1995;47:90-5.

19 McElveen C, Carvajal MV, Moscatello D, Towner J, Lacassie Y. Ectrodactyly and proximal/intermediate interstitial deletion 7q. Am 7 Med Genet 1995;56:1-5.

20 Cobben JM, Verheij JB, Eisma WH, et al. Bilateral split hand/foot malformation and inv( $\overline{7}) \mathrm{p} 22 \mathrm{q} 21.3)$. $₹$ Med Genet hand/foot malfo

21 Palmer SE, Scherer SW, Kukolich M, et al. Evidence for locus heterogeneity in human autosomal dominant split hand/split foot malformation. Am $\mathcal{F}$ Hum Genet 1994;55: 21-6.

22 Gurrieri F, Genuardi M, Chiurazzi P, Gillessen-Kaesbach G, Neri G. Exclusion of linkage between autosomal dominant split hand/split foot and markers from chromosome $7 \mathrm{q}$ : further evidence for genetic heterogeneity. $\mathrm{Am} 7 \mathrm{Hum}$ Genet 1994;55:853-5.

23 Cremer T, Landegent J, Bruckner A, et al. Detection of chromosome aberrations in the human interphase nucleus by visualization of specific target DNAs with radioactive and non-radioactive in situ hybridization techniques: nosis of trisomy 18 with probe L.184. Hum Genet 1986; 74:346-52.

24 Scherer SW, Poorkaj P, Massa $\mathrm{H}$, et al. Physical mapping of the split hand/split foot locus on chromosome 7 and implication in syndromic ectrodactyly. Hum Molec Genet implication in synd

25 Crackower MA, Scherer SW, Rommens JM, et al. Characterization of the split hand/split foot malformation locus SHFM1 at 7q21.3-q22.1 and analysis of a candidate gene for its expression during limb development. Hum Molec Genet (in press)

26 Trask BJ. Fluorescence in situ hybridization: a review of the role of FISH in genome analysis, supporting background information, and detailed protocols. In: Birren B, Green E, Hieter P, Myers R, eds. Genome analysis: a laboratory manual. New York: Cold Spring Harbor Laboratory Press, 